\title{
Mortality pattern of chronic kidney disease of uncertain etiology in Girandurukotte, Sri Lanka
}

T.W. Hettiarachchi, M.A.A. Nayanamali*, T. Sudeshika, W.B.N.T. Fernando, Z. Badurdeen, S. Nanayakkara, S. Wijetunge, L. Gunaratne and N. Nanayakkara

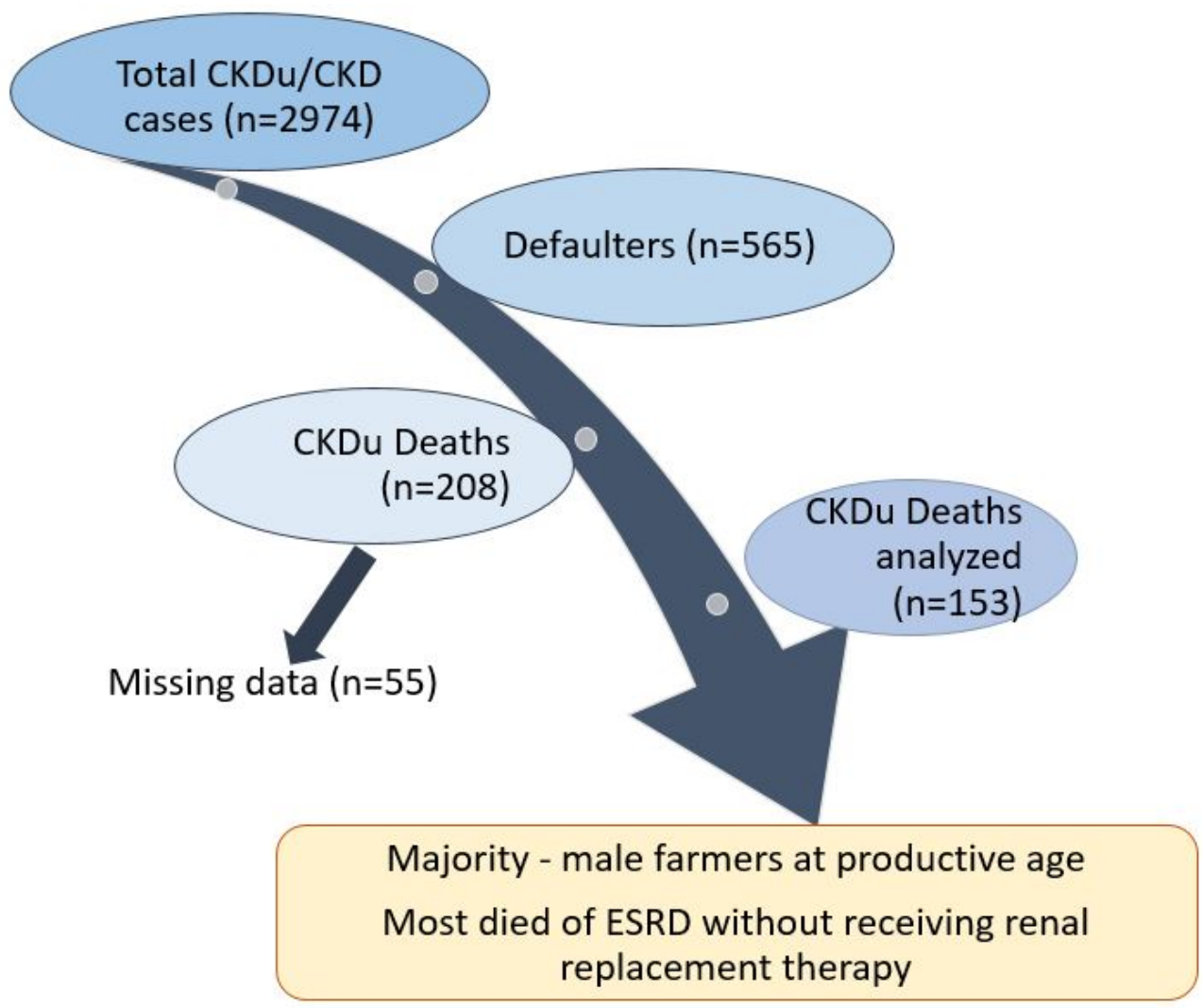

\section{Highlights}

- Majority of patients died from CKDu were young, male farmers.

- Only $5.88 \%$ of the population had received renal replacement therapy before death.

- The immediate cause for death was end-stage renal disease (ESRD).

- Developing strategies to minimize the progression of CKDu to ESRD is crucial. 
SHORT COMMUNICATION

\title{
Mortality pattern of chronic kidney disease of uncertain etiology in Girandurukotte, Sri Lanka
}

\author{
T.W. Hettiarachchi ${ }^{1}$, M.A.A. Nayanamali ${ }^{2,3^{*}}$, T. Sudeshika ${ }^{4}$, W.B.N.T. Fernando ${ }^{1,5}, Z^{2}$ Badurdeen $^{1}$, S. Nanayakkara ${ }^{6}$, \\ S. Wijetunge ${ }^{7}$, L. Gunaratne ${ }^{8}$ and N. Nanayakkara ${ }^{2}$
}

\author{
${ }^{1}$ Center for Education, Research and Training on Kidney Diseases (CERTKiD), Faculty of Medicine, University of \\ Peradeniya, Peradeniya, Sri Lanka. \\ ${ }^{2}$ Nephrology and Transplant Unit, National Hospital, Kandy, Sri Lanka. \\ ${ }^{3}$ Department of Fundamental Nursing, Faculty of Nursing, University of Colombo, Colombo, Sri Lanka. \\ ${ }^{4}$ Department of Pharmacy, Faculty of Allied Health Sciences, University of Peradeniya, Peradeniya, Sri Lanka. \\ ${ }^{5}$ Department of Medical Laboratory Science, Faculty of Allied Health Sciences, University of Ruhuna, Galle, Sri Lanka. \\ ${ }^{6}$ School of Dentistry, Faculty of Medicine and Health, The University of Sydney, NSW, 2006, Australia. \\ ${ }^{7}$ Department of Pathology, Faculty of Medicine, University of Peradeniya, Peradeniya, Sri Lanka. \\ ${ }^{8}$ Renal Care Unit, Divisional Hospital Girandurukotte, Sri Lanka.
}

Received: 11/12/2020; Accepted: 10/06/2021

\begin{abstract}
Mortality in Chronic Kidney Disease of uncertain etiology $(\mathrm{CKDu})$ is not well described despite being a major public health crisis in Sri Lanka. Data on CKDu have many gaps and published data on mortality are sparse. This retrospective descriptive study was designed to describe the mortality of CKDu in an endemic area. Deaths were identified by tracing clinic defaulters from 2005 to 2015 in renal clinic, Girandurukotte. The majority who passed away were male $(83.70 \%)$ farmers $(80.39 \%)$ in their productive age (mean age $58.0 \pm 13.01$ ). Immediate cause of death was end-stage renal disease (ESRD) in $94.12 \%$ of deaths, reflecting the unavailability of Renal Replacement Therapy (RRT). Therefore, strategies are urgently required to enhance early identification, to provide standard medical care and to expand RRT in CKDu affected areas.
\end{abstract}

Keywords: Mortality; chronic kidney disease of uncertain etiology $(\mathrm{CKDu})$; renal replacement therapy (RRT); end-stage renal disease (ESRD).

\section{INTRODUCTION}

Chronic kidney disease of uncertain etiology ( $\mathrm{CKDu})$ has been described as an emerging public health problem in developing countries since early 1990 (Ranasinghe et al., 2019). In Sri Lanka, this new form of tubular interstitial nephropathy was first recognized in the North Central Region (Edirisinghe et al., 2018). Despite being the focus of many research, the cause of disease remains a mystery. Hence, there is no certainty on the effectiveness of the current preventive measures in reducing the disease burden. In the same line, very limited published data is available on mortality in CKDu.

Mortality is substantially high in patients with CKD (Bikbov et al., 2020). The disease invariably progressed into end-stage renal disease (ESRD), requiring renal replacement (RRT), if not died of other reasons. At this stage, patients have major cardiovascular, metabolic and cognitive disorders leading to high mortality (Delgado et al., 2017). Hence, therapeutic strategies to prevent the progression and the availability of RRT are extremely important to enhance the survival of CKD patients.

According to the studies conducted worldwide, CKD resulted in 1.2 million deaths in 2017. Mortality of CKD is ever rising and it was ranked as the $17^{\text {th }}$ cause for deaths in 2012 and became the $12^{\text {th }}$ in 2017 (Bikbov et al., 2020). Following the same pattern, CKD became the eighth leading cause of in-hospital mortality in 2016 from $12^{\text {th }}$ in 2012, and one of the leading causes of deaths in some regions of Sri Lanka (Annual Health Statistics, Sri Lanka, 2016). A study on CKD and CKDu in North Central Province of Sri Lanka reported that, 6\%, 17.5\% and $21.4 \%$ of total deaths within five years were reported in first, second and third years after the diagnosis. Further, the same study has concluded that the pattern is not uniform among all divisional secretariat divisions in North Central Province. The high disease prevalence and mortality had been clustered around paddy fields and irrigation tanks causing a burden to the Sri Lankan economy (Ranasinghe et al., 2019). Even though CKDu is identified as However, a major public health issue in Sri Lanka, the mortality pattern of CKDu has not been well documented yet. Thus, present study was conducted to investigate the mortality pattern of CKDu. More importantly, this is the first study reporting the mortality of the observational cohort of $\mathrm{CKDu}$ in Girandurukotte, Sri Lanka.

\section{MATERIALS AND METHODS}

Girandurukotte administrative division with a total population of forty thousand is located in the Uva Province of Sri Lanka. The area had been identified as high prevalent for $\mathrm{CKDu}$, after a total population screening conducted in 


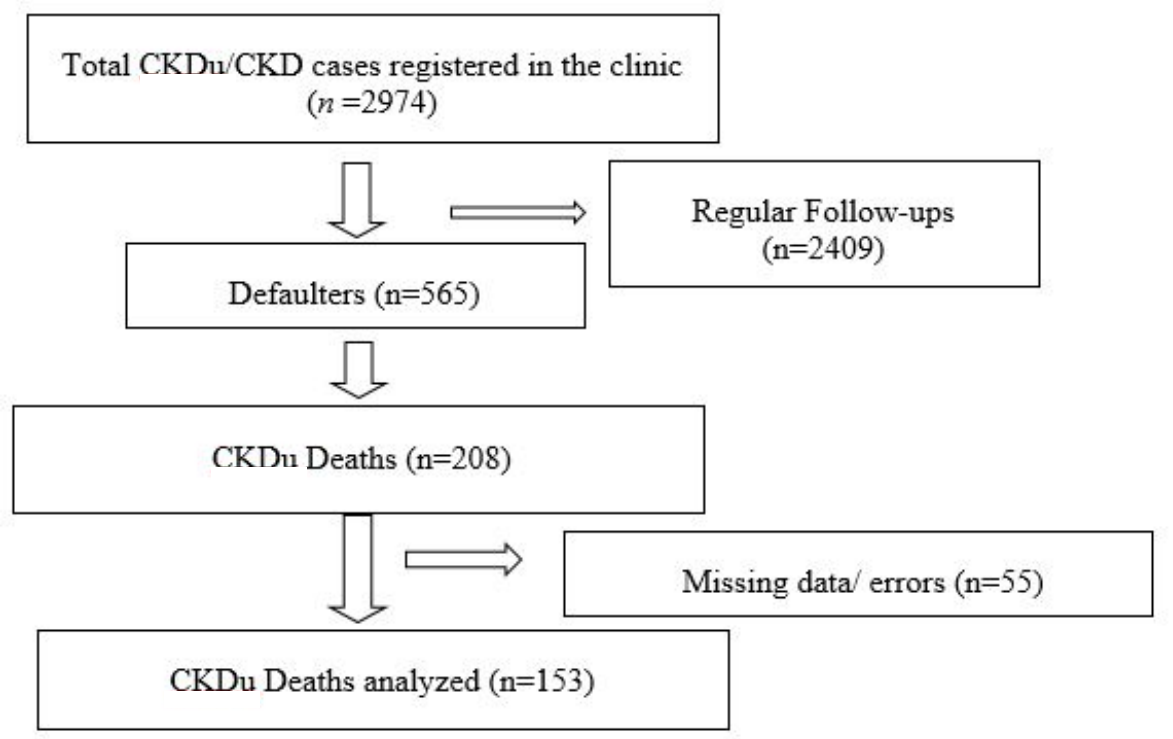

Figure 1: Flow chart of the study population.

Legend: CKDu- chronic kidney disease of uncertain aetiology, CKD- Chronic kidney disease.

Table 1: Baseline characteristics of the deceased CKDu patients.

\begin{tabular}{cccc}
\hline Characteristics & $\begin{array}{c}\text { Deaths } \\
(\mathbf{n}=\mathbf{1 5 3})\end{array}$ & $\begin{array}{c}\text { Male } \\
(\mathbf{n}=\mathbf{1 2 8})\end{array}$ & $\begin{array}{c}\text { Female } \\
(\mathbf{n = 2 5})\end{array}$ \\
\hline Occupation; Farmer n (\%) & $123(80.39)$ & $115(93.49 \%)$ & $8(6.50 \%)$ \\
Age (years) at the death & $58.0 \pm 13.01$ & $56 \pm 12.78$ & $55 \pm 14.75$ \\
Years from diagnosis to death (Mean \pm SD) & $5.27 \pm 3.40$ & $4.97 \pm 3.34$ & $6.80 \pm 3.53$ \\
\hline
\end{tabular}

Legend: n- Number, SD- standard deviation.

2005 (Jayasekara et al., 2013). The diagnosis of CKDu has been established, after excluding known causes of CKD by clinical, laboratory, ultrasound scans and if indicated after histological evaluation. All confirmed patients were logged into a clinic registry and each patient was given a unique reference number. Subsequent referrals from regional clinics were entered into the registry following the same protocol. All patients were longitudinally followed up and provided treatment according to kidney disease outcomes quality initiative (KDOQI) guidelines. Following the usual practice, individual clinical records were kept with the patients and were monthly updated by the medical staff in the renal clinic.

All patients who failed to attend the follow-up clinics for consecutive six months or more during the study period (2005-2015) were identified from the clinic records. The cause of absence was investigated with the support of the public health team, administrative officers and relatives of the absentees. After extraction of data, all data fields were checked for their completeness, accuracy and internal consistency. Data were entered into an excel sheet and analyzed using IBM SPSS Statistics (version 22, IBM SPSS Inc., Chicago, IL).

Ethical clearance was obtained from the Institutional Ethical Review Committee (IERC), Faculty of Medicine, University of Peradeniya, Sri Lanka. (Reference No: 2016/ EC/29).

\section{RESULTS}

First total population screening program in Girandurukotte was conducted in 2005. Up to 2015, 2974 CKD patients were identified and registered in the renal clinic. Among them, $565(19 \%)$ patients did not attend the follow-up clinics for more than six consecutive months. Out of nonattendees, $208(7 \%)$ succumbed to death. There were no records to identify the cause of death in 55 events. Hence, remaining 153 deaths with death certificates and/or hospital records of final admission were included in further analysis. The study flow chart is shown in Figure 1.

Accordingly, the male to female ratio was 1.6: 1 and the mean age of the deceased was $56 \pm 12.78$ years for males and it was $55 \pm 14.75$ years for females. Majority of the deceased patients were farmers $(n=123,80.39 \%)$ of which $93.5 \%(n=115)$ were males. Among the females, $60 \%$ were housewives. Table 1 shows the baseline characteristics of the study sample. Only nine patients $(5.88 \%)$ of the deceased had received RRT, where $3.92 \%$ $(n=6)$, were on hemodialysis, $0.65 \%(n=1)$ on peritoneal dialysis and $1.31 \%(n=2)$ had a kidney transplant. The immediate cause of death had been recorded as an ESRD in $94.12 \%(n=144)$ of the patients. Cardiovascular disease (CVD) accounted only for $2.60 \%(n=4)$ of the deaths while the rest have succumbed to other causes such as cancer ( $\mathrm{n}=$ 2 ), severe bladder outflow obstruction $(n=1)$, hypokalemia $(\mathrm{n}=1)$ and cirrhosis $(\mathrm{n}=1)$. 


\section{DISCUSSION}

$\mathrm{CKDu}$ is found to be prevalent in discrete geographical locations of some tropical countries such as Sri Lanka, El Salvador, Nicaragua, Egypt and India (Gifford et al., 2017). As the name implies, exact causative factors of the disease are obscure, despite many scientific studies. There are only limited reports and published information available on the mortality of CKDu even though it is a major public health problem which should be highly concerned. Studying the mortality pattern of CKDu in Sri Lanka is challenging due to the unavailability of a systematic reporting system or detailed, regularly updated centralized database for the disease. In developing countries, specifically in rural regions of Sri Lanka, medical record-keeping is not comparable to electronic data bases in developed countries. Patients' medical records are handwritten and under the possession of the patient. There is no proper mechanism to report deaths to the health system to update registries in hospitals. Once a patient died, all health records make unavailable for the health system. Thus, a proper evaluation of mortality in $\mathrm{CKDu}$ especially in retrospective settings was challenging.

For the first time, this study reports the data on mortality of $\mathrm{CKDu} / \mathrm{CKD}$ in Girandurukotte; a CKDu-high prevalent area. It is important to note that the majority of the deceased were males at their productive age and most were farmers. The high death counts reported on males reflect the higher prevalence of disease among males (Ranasinghe et al., 2019). Similarly, deaths in higher proportion of farmers may represent the predominant occupation in the area or causal relationship of the disease to the farming.

Both men and women with lower levels of kidney function had substantially reduced life expectancy, which was most notable in those with eGFR $<30$. In general, women had a longer life expectancy than men across all levels of eGFR and age, except for those with eGFR 15-29 (Turin et al., 2012). Despite in CKDu, in the current study, women had lesser mean age expectation than men. Another significant point is that a majority of deaths were around the age of fifty-five years in CKDu patients which is remarkably lower than the average life expectancy (76.81 years) for Sri Lankans.

Similar to most resource limited countries in the world, in Sri Lanka, there is no universal access to health care, especially for costly and complicated treatments like RRT (Rope et al., 2018). At the time of the study, patients had to travel, at least hundred kilometers to the nearest dialysis unit to receive dialysis. However, now there are several ongoing programs on the establishment of continuous ambulatory peritoneal dialysis CAPD and to expand hemodialysis in this area (Rope et al., 2018). Nonetheless, in the current analysis, it is obvious that a majority of the deceased have not received RRT. Deaths from CVD or infection were higher at lower eGFR (Thompson et al., 2015). Likewise, CVDs (including an increase in heart failure and valvular disease) have been reported as the main cause of death in CKD (Alani et al., 2014). According to our results, CVDs accounted for only $2.61 \%$ and the major proportion of deaths were due to end-stage renal failure, This may occur due to the lower prevalence of CVD among CKDu in comparison to CKD (Hettiarachchi et al., 2021)

The current study has several limitations, since most deaths occurred away from hospital facilities, the latest eGFR before death was not available. Furthermore, we were unable to find the course of death in a significant percentage which can have an impact on the results.

\section{CONCLUSION}

The main cause of death in CKDu cohort was ESRD and the majority had not received RRT which is lifesaving. Unlike in CKD, cardiovascular deaths were not prominent in CKDu. The results of this study warrant, immediate interventions to improve the prognosis of affected individuals from this fatal disease in rural farming communities of Sri Lanka.

\section{ACKNOWLEDGEMENT}

Authors are thankful to Dr. Thilak Abeysekara, Centre for education research and training on Kidney diseases, Faculty of Medicine, University of Peradeniya, Peradeniya, Sri Lanka; public health midwives at Girandurukotte $\mathrm{MOH}$ area; and staff of the Renal Centre at Girandurukotte, Sri Lanka.

\section{DECLARATION OF CONFLICT OF INTEREST}

The authors have declared that no competing interests exist.

\section{REFERENCES}

Alani, H., Tamimi, A. and Tamimi, N. (2014). Cardiovascular co-morbidity in chronic kidney disease: Current knowledge and future research needs. World Journal Nephrology 3(4):156-68.

Sri Lanka, Medical Statistics Unit Ministry of Health, Nutrition and Indigenous Medicine, Colombo (2016). Annual Health Statistics. Available from: http://www. health.gov.lk > files > AHB > AHS 2016/ (5 July 2021).

Bikbov, B., Purcell, C.A., Levey, A.S., Smith, M., Abdoli, A., Abebe, M. and Owolabi, M.O. (2020). Global, regional, and national burden of chronic kidney disease, 1990-2017: a systematic analysis for the Global Burden of Disease Study 2017. The Lancet 395(10225): 709733.

Delgado, C.E.Y., Dávila, S.P., Jaramillo, M.M. and Orozco, B.E.O. (2017). Stage progression and need for renal replacement therapy in a renal protection programme in Colombia. A cohort study. Nefrología (English Edition) 37(3): 330-337.

Edirisinghe, E.A.N.V., Manthrithilake, H., Pitawala, H.M.T.G.A., Dharmagunawardhane, H.A. and Wijayawardane, R.L. (2018). Geochemical and isotopic evidences from groundwater and surface water for understanding of natural contamination in chronic kidney disease of unknown etiology (CKDu) endemic zones in Sri Lanka. Isotopes in Environmental and Health Studies 54(3): 244-261.

Gifford, F.J., Gifford, R.M., Eddleston, M. and Dhaun, N. (2017). Endemic nephropathy around the world. Kidney International Reports 2(2): 282-292. 
Hettiarachchi, T.W., Fernando, B.N.T.W., Sudeshika T., Badurdeen Z., Anand S., Kularatne A., Wijetunge S., Abeysundara H.T.K. and Nanayakkara N. (2021). Prevalence, risk factors and predicted risk of cardiac events in chronic kidney disease of uncertain aetiology in Sri Lanka: A tubular interstitial nephropathy. PloS one 16(4): e0249539.

Jayasekara, J.M., Dissanayake, D.M., Adhikari, S.B. and Bandara, P. (2013). Geographical distribution of chronic kidney disease of unknown origin in North Central Region of Sri Lanka. Ceylon Medical Journal 58(1): 6-10.

Ranasinghe, A.V., Kumara, G.W.G.P., Karunarathna, R.H., De Silva, A.P., Sachintani, K.G.D., Gunawardena, J.M.C.N., Kumari, S.K.C.R.K., Sarjana, M.S.F., Changaraguptha, J.S. and De Silva, M.V.C. (2019). The incidence, prevalence and trends of Chronic Kidney Disease and Chronic Kidney Disease of uncertain aetiology $(\mathrm{CKDu})$ in the North Central Province of Sri Lanka: an analysis of 30,566 patients. BMC Nephrology 20(1): 1-11.

Rope, R., Nanayakkara, N., Wazil, A., Dickowita, S., Abeyeskera, R., Gunerathne, L. and Saxena, A. (2018). Expanding CAPD in low-resource settings: a distance learning approach. Peritoneal Dialysis International
38(5): 343-348.

Thompson, S., James, M., Wiebe, N., Hemmelgarn, B., Manns, B., Klarenbach, S. and Tonelli, M. (2015). Cause of death in patients with reduced kidney function. Journal of the American Society of Nephrology 26(10): 2504-2511.

Tonelli, M., Wiebe, N., Culleton, B., House, A., Rabbat, C., Fok, M., McAlister, F. and Garg, A. X. (2006). Chronic kidney disease and mortality risk: a systematic review. Journal of the American Society of Nephrology 17(7): 2034-2047.

Turin, T. C., Tonelli, M., Manns, B.J., Ravani, P., Ahmed, S.B. and Hemmelgarn, B.R. (2012). Chronic kidney disease and life expectancy. Nephrology Dialysis Transplantation 27(8): 3182-3186.

Wijewickrama, E.S., Gunawardena, N., Jayasinghe, S. and Herath, C. (2019). CKD of unknown etiology (CKDu) in Sri Lanka: a multilevel clinical case definition for surveillance and epidemiological studies. Kidney International Reports 4(6): 781-785.

World Health Organization. (2012). Investigation and evaluation of chronic kidney disease of uncertain etiology in Sri Lanka. Final report, World Health Organization, Geneva, Switzerland. Available from: https://www.who.int > gho > EN_WHS2012 (5 $5^{\text {th }}$ July 2021). 